\title{
Experimental study by visualisation of behavioural properties of vortex structures on the upper surface of an ogive of revolution $\beta 52^{\circ}$
}

\author{
Abderrahmane Abene \\ Université de Valenciennes, Laboratoire d'Aérodynamique, d'Energétique et de l'Environnement, I. S. T. V, Valenciennes, 59300 Aulnoy lez \\ valenciennes France
}

Email address:

a.abene@yahoo.fr

\section{To cite this article:}

Abderrahmane Abene, Le Mont-Houy. Experimental Study by Visualisation of Behavioural Properties of Vortex Structures on the Upper Surface of an Ogive of Revolution $\beta 52^{\circ}$. International Journal of Mechanical Engineering and Applications.

Vol. 2, No. 5, 2014, pp. 70-77. doi: 10.11648/j.ijmea.20140205.13

\begin{abstract}
A large number of studies of flow visualisations, developed on the upper surface of delta or gothic wings and on that of ogives of revolution, have been carried out in the wind tunnel of the Valenciennes University aerodynamics and hydrodynamics laboratory (LAH). These studies have provided a better understanding of the development and the positioning of vortex structures and have enabled, in particular, the preferential nature of intervortex angles, thereby defined, to be determined on a wide range of Reynolds. This paper concerns in particular the study by visualisations of the behavioural properties on the upper surface of an ogive of revolution having an apex angle of $68.6^{\circ}$ at a low angle of attack and conducted at variable speeds. It has been noted that variations in speed have no influence at all on the behavioural properties of the development of vortex structures whereas, by contrast, changes to the angles of incidence do indeed strongly influence that development. The study of the ascent of the vortex breakdown at high angles of attack has revealed original behavioural properties which find expression notably in the discontinuous evolution, in terms of the apex angle, of those angles of attack which define the beginning and the end of the ascent of this vortex breakdown. These properties undoubtedly reflect those already observed in similar studies carried out on delta and gothic wings and on cones. However, no current theory seems to be able to provide a straightforward explanation of these phenomena.
\end{abstract}

Keywords: Vortex, Visualization, Structures, Reynolds, Speed

\section{Introduction Reynolds}

The concept of a preferential angle was introduced for the first time in 1972 by M. LE RAY and his colleagues and stems from their studies of liquid helium $[1,2]$. These angles, which have the following relatively simple analytic formula:

$$
\operatorname{Cos} \theta_{\ell m}=\frac{\mathrm{m}}{\sqrt{\ell(\ell+1)}} \text { where } \ell \geq \mathrm{m}
$$

can be classified by their most frequent values into two groups :

1st group :

$(\ell=\mathrm{m}): \theta_{11}=45^{\circ} ; \theta_{22}=35.3^{\circ}, \theta_{33}=30^{\circ}, \theta_{44}=26.6^{\circ}, \theta_{55}=$ $24.1^{\circ}, \theta_{66}=22.2^{\circ}, \theta_{77}=20.7^{\circ}, \theta_{88}=19.4^{\circ}, \theta_{99}=18.4^{\circ}$

2nd group :

$(\mathrm{m}=2): \theta_{22}=35.3^{\circ}, \theta_{32}=54.7^{\circ}, \theta_{42}=63.4^{\circ}, \theta_{52}=68.6^{\circ}$, $\theta_{62}=72^{\circ}, \theta_{72}=74.5^{\circ}, \theta_{82}=76.4^{\circ}, \theta_{92}=77.8^{\circ}$

A particularly high number of studies have been carried out to date into delta or gothic wings and into some combinations of such components that form more or less simple slender bodies; they have dealt as much with the development of approximate theories as with the definition of models specifying vortex lift per unit area.

Visualisations of hyperlifting vortex structures, mainly those carried out by H. WERLE [3 to 9], the analysis of pressure fields and of speeds created by these vortices, with or without their bursting, notably J.L. SOLIGNAC's analysis $[10,11]$, also provide quite outstanding studies that are the standard works in their field. Already described fully in such papers as those by W. STAHL and A. ASCHAR [12 to 13], these studies offer today in their entirety, a thorough knowledge of the properties of various types of slender bodies. 
However, given that the character of most of the aspects referred to remain empirical and limited to this or that angle of incidence [ 3 to 18 ] or to a numeric field, the way lies open, starting out from experimental data and various factors of analysis [19 to 21], for new attempts to be undertaken to examine the fundamental problems related to the positioning of vortices created by such slender bodies.

A large number of photographic and videographic visualisations concerning vortex flows developed on the upper-surface of delta or gothic wings and of cones $[33,34]$ have been carried out within the Valenciennes University laboratory with a view to providing a better understanding of the development and the positioning of vortex structures under the influence of apex angles and angles of incidence. These visualisations have enabled priority to be accorded to the study of examples of the most elementary shaped bodies, i.e. delta and gothic wings. The results obtained, and already fully described in previous papers [19 to 23], have been expressed by some very simple mathematical formulae; that very simplicity perhaps calls for some essential explanations.

The angles between the vortices have, in fact, been found, on a wide range of Reynolds, to have a preferential nature, thereby underlining a simple angular characterisation of the positioning relative to the vortex torques. Moreover, it is worth recalling here that vortices appeared as single or double structures depending on the nature of the apex angle. The studies carried out on such slender bodies have enabled the conditions of the existence of secondary vortex torques to be determined. We have shown in particular that the vortex structure developed on the upper surface of delta wings is a double one for non preferential or preferential angles but only for those higher than $45^{\circ}$. In the same way, the vortex structure developed on the upper surface of gothic wings has been shown to be a double one for both non preferential and preferential angles but only when they are higher than or equal to $68.6^{\circ}$.

However, in either case, we have been able to formulate a simple law, called the law of filiation, which expresses a notable angular relationship between the main vortex structure and the leading edges characterised by an apex angle from the 1st group [22 , 23, 37 and 38]. Simultaneously, studies carried out on the cone enabled the existence of preferential intervortex angles to be confirmed [22].

Vortex torques developed on the upper surface of the ogive of revolution were generally shown to have double structures, a finding which raises the delicate fluid equivalence question of the leading edges of the delta wing. We have also, by analogy with the law of filiation referred to above, been able to monitor an angular characterisation of similar simplicity but one which expresses a notable relationship between the main and secondary vortex structures. This new behavioural property, equally called the law of filiation, without doubt concerns the ogive of revolution as a whole. Limited as it is to the case of an ogive of revolution having an apex angle of $68.6^{\circ}$, our present study can consequently only be taken as an example, albeit a detailed one, of this phenomenon.

\section{Models Used in the Experiment}

The various models subjected to trials in the wind tunnel are of the circular-base cone-shaped type.

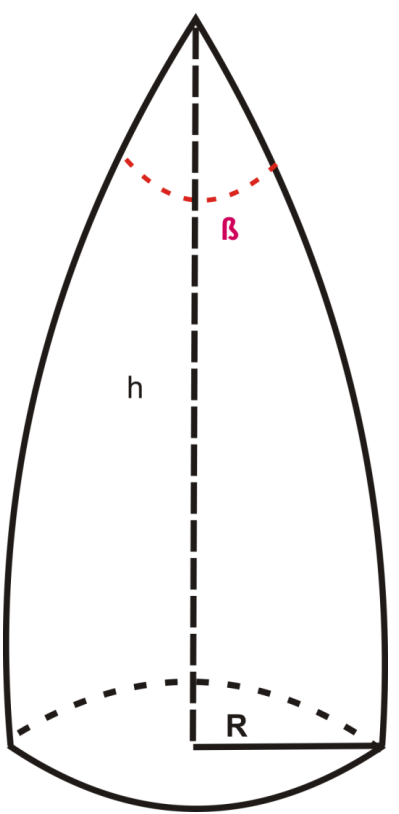

Diagram $n^{\circ} 1$. The principles of constructing an ogive of revolution

$\beta$ : summit (apex) angle

$\mathrm{h}$ : height of the ogive of revolution

$\mathrm{R}$ : radius of circular base

\section{Visualisation Techniques}

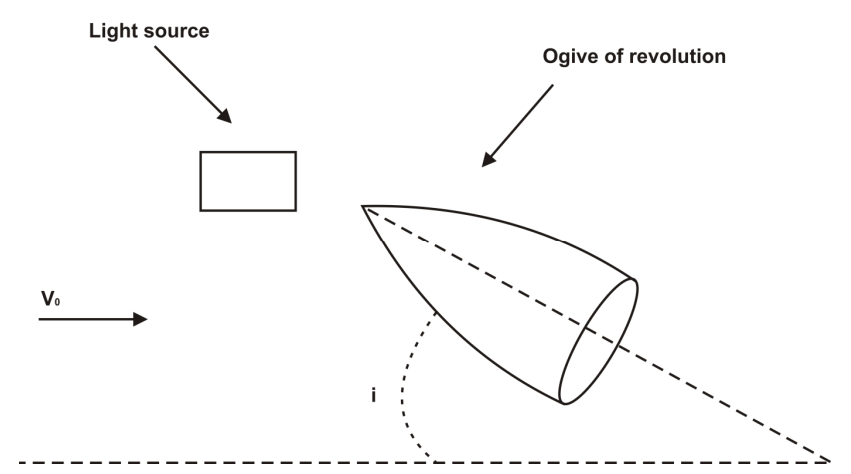

Diagram $n^{\circ} 2$. Diagrammatic representation of the experimental device

i : incidence

$\mathrm{v}_{\mathrm{o}}$ : speed of flow to infinity upstream

The visualisations in their entirety were carried out within the test section of the wind tunnel $\left\{\right.$ a $45 \times 45 \mathrm{~cm}^{2}$ section $\}$ at the LAH. The vortex structures developed on the upper surface were made visible by providing for emissions of white smoke at the ogive of revolution tip; this was obtained by injecting oil under pressure through a tube of small diameter and then, by means of an integrated electrical system, vaporising the oil immediately as it left the probe. The ogive of revolution was fixed onto an axis relayed to a cursor graduated from $0^{\circ}$ to $360^{\circ}$ which enabled the incidence of inclination to be varied. The visualisations were 
captured on photographs and videofilm which are today stored in the department's database.

\section{Conditions under which the Experiments were Carried Out}

Visualisations, employing smoke, were carried out at low speed ( $\mathrm{v}=3$ to $5 \mathrm{~m} / \mathrm{s}$ ) which gives the flow a Reynolds' number ranging from 19000 to 80000 h: length of reference $\}$. The height $h$ and the apex angle $\beta$ of the ogive of revolution are respectively $110 \mathrm{~mm}$ and $68.6^{\circ}$. The incidence i varies over a range of from $25^{\circ}$ to $65^{\circ}$.

\section{Results of the Experiments}

In order to avoid rendering this paper unduly lengthy, we summarise the findings by stating simply that visualisations at increasing incidence enabled the progressive birth of vortex structures to be carefully monitored; at mean incidence, these structures become concentrated and stable and thus pass from a structure of flow with raised edges to the standard vortex tube structures.

Those vortices derived from the apex and perfectly described by H. WERLE [8], result in fact from the "cornet-like" spiral coiling of the flow which detaches itself from each side of the streamlined body. Their axes are rectilinear and are cut near the apex depending on the angles \{respectively interior and exterior $\omega_{1}$ and $\left.\omega_{2}\right\}$ while the pace of the pseudo-flow in a transversal plane is probably close to that which figures in diagram $n^{\circ} 3$ where the external vortices are closer to the wall than are the interior ones.

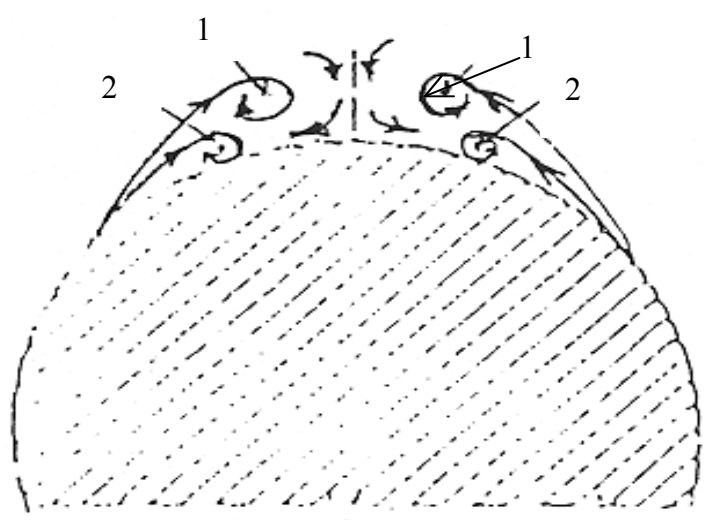

Diagram $n^{\circ} 3$. Vortex to turn your exterior and interior inverse sense and variable speed [22to33].

1: interior vortex

2: exterior vortex

Whatever the incidence, these intervortex angles have shown themselves to have a preferential nature and have proved to be especially stable since they do not depend, in the conditions applied to the experiment, on speed for on Reynolds $\}$. However, it is worth noting that such angles, contrary to what takes place on the upper surface of delta or gothic wings, even so depend on the incidence, a fact which bestows on them a discontinuous evolution since they have a tendency to conserve their preferential aspect $\left\{\right.$ see graph $\left.n^{\circ} 1\right\}$.

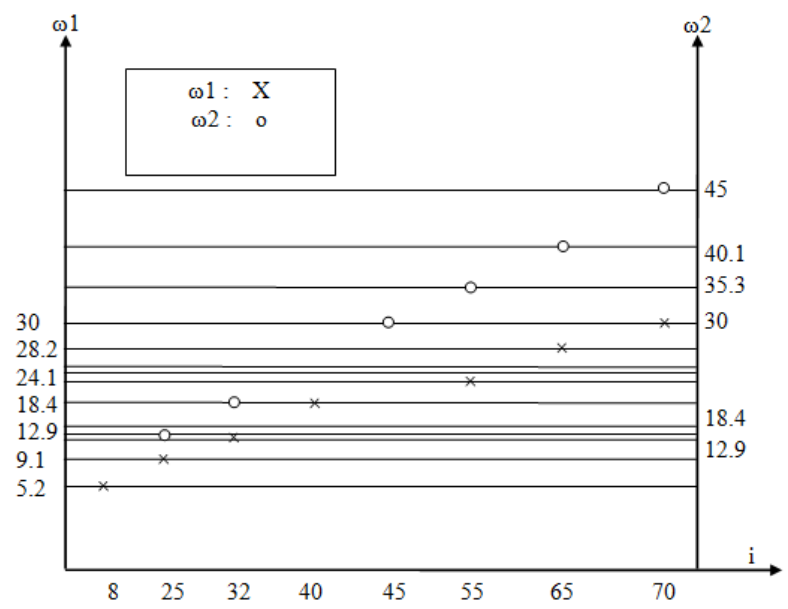

Graph $n^{\circ} 1$. The evolution of interior and exterior intervortex angles in relation to the incidence $19000<R e<80000$

Moreover, we noticed that there existed, in every case, a notable correspondence between both the interior and exterior intervortex angles. It has in fact been confirmed that the intervortex angles $\omega_{2}$, in their entirety, belong to the first group of preferential angles $\left\{\right.$ those with the notation $\left.\theta_{\ell \ell}\right\}$ and consequently infer, in accordance with the law of filiation, that the intervortex angles $\omega_{l}$ are also of the same first group $\left\{\right.$ see Table $\left.n^{\circ} 1\right\}$ but with the notation

$$
\begin{gathered}
\theta_{2 \ell+1,2 \ell+1} \\
\omega_{2}=\theta_{\ell \ell} \rightarrow \omega_{1}=\theta_{2 \ell+1,2 \ell+1}
\end{gathered}
$$

Table $n^{\circ} 1$. Angular relationship between interior and exterior intervortex angles (in degrees) $19000<\operatorname{Re}<80000$

\begin{tabular}{lllll}
\hline $\mathbf{i}$ & $\mathbf{w}_{\mathbf{2}}$ & & $\mathbf{w}_{\mathbf{1}}$ & \\
\hline 8 & 8.7 & $\mathrm{q}_{39.39}$ & 5.2 & $\mathrm{q}_{45.45}$ \\
25 & 12.9 & $\mathrm{q}_{29.29}$ & 9.1 & $\mathrm{q}_{39.39}$ \\
32 & 18.4 & $\mathrm{q}_{19.19}$ & 12.9 & $\mathrm{q}_{29.29}$ \\
35 & 19.4 & $\mathrm{q}_{9.9}$ & 13.6 & $\mathrm{q}_{21.21}$ \\
40 & 26.6 & $\mathrm{q}_{8.8}$ & 18.4 & $\mathrm{q}_{19.19}$ \\
45 & 30 & $\mathrm{q}_{4.4}$ & 20.7 & $\mathrm{q}_{17.17}$ \\
50 & 35.3 & $\mathrm{q}_{3.3}$ & 24.1 & $\mathrm{q}_{9.9}$ \\
55 & 35.3 & $\mathrm{q}_{2.2}$ & 24.1 & $\mathrm{q}_{7.7}$ \\
58 & 40.1 & $\mathrm{q}_{2.2}$ & 28.2 & $\mathrm{q}_{5.5}$ \\
62 & 45 & $\mathrm{q}_{11}$ & 30 & $\mathrm{q}_{3.3}$ \\
\hline
\end{tabular}

This law, established in the particular case of the ogive of revolution, inevitably refers back to the quite analogous results we observed [22 and 23] from our studies of gothic wings and cones and of delta wings even if, in the case of gothic wings, the notable angular correspondence was described between the apex angles $\beta$ of the first group and the associated intervortex angle $\alpha$.

$$
\beta=\theta_{\ell \ell} \rightarrow \alpha=\theta_{2 \ell+1,2 \ell+1}
$$

Be that as it may, the description of the behavioural law 
may be taken a little further if we make a point of referring again to the first definition of preferential angles, namely :

$$
\operatorname{Cos} \theta_{\ell \ell}=\frac{\ell}{\sqrt{\ell(\ell+1)}}
$$

In these conditions,

$$
\begin{gathered}
\sin ^{2} \theta_{\ell \ell}=1+\cos ^{2} \theta_{\ell \ell}=\frac{1}{\ell+1} \\
\sin ^{2} \theta_{2 \ell+1,2 \ell+1}=\frac{1}{2(\ell+1)}
\end{gathered}
$$

which can be simplified to :

$$
\sin ^{2} \theta_{2 \ell+1,2 \ell+1}=\frac{\sin ^{2} \theta_{\ell \ell}}{2}
$$

and thus :

$$
\sin ^{2} \omega_{1}=\frac{\sin ^{2} \omega_{2}}{2}
$$

Some of the visualisations obtained, where incidences were increasing from $25^{\circ}$ to $55^{\circ}$, provide a better appreciation of the evolution of vortex structures developed on the upper surface of an ogive of revolution having an included angle of $68.6^{\circ}$ see Views $n^{\circ} 1,2,3,4$ and 5\}. However, it is worth noting that even at a higher incidence of $65^{\circ}$, we can notice the existence of two flows separated by an interval not fed by smoke and thus constituting a non vortex passage $\left\{\right.$ see View $\left.n^{\circ} 6\right\}$.

Incidence of An angle of $32^{\circ}$

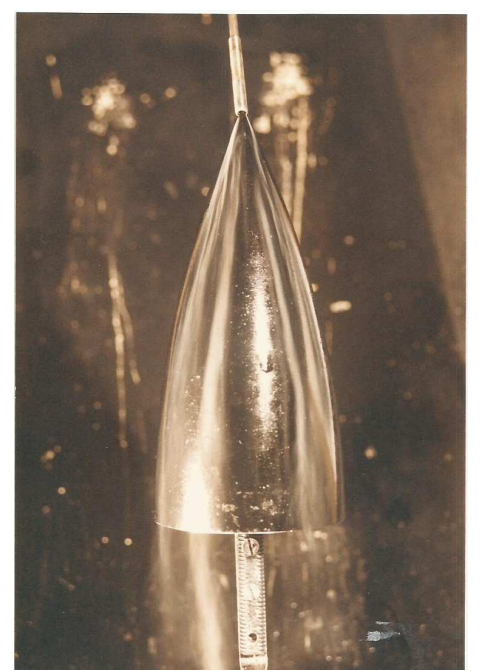

View $\boldsymbol{n}^{\circ} 1$. An angle incidence of $8^{\circ}$; the flow is uniform on the upper side of the wing. The boundary layer is observed but there is non flow separation as yet.

$\beta=52^{\circ} \quad \mathrm{i}=32 \quad \omega 1=12.9^{\circ} \quad \omega 2=18.4^{\circ}$

$19000<\operatorname{Re}<80000$

$$
\text { Incidence of An angle of } 40^{\circ}
$$

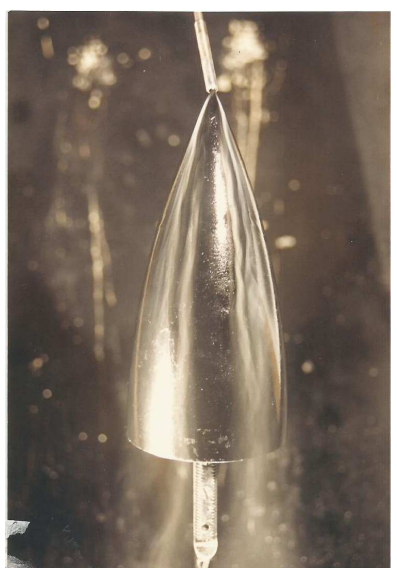

View $n^{\circ}$ 2. When the incidence is increased, the main vortices and the secondary vortex torque are now observed, the speed remaining constant. However, variation in the speed have no effect at all on the formation of vortex angle of $32^{\circ}$

$\beta=52^{\circ} \quad \mathrm{i}=40^{\circ} \quad \omega 1=18,4^{\circ} \quad \omega 2=26,6^{\circ}$

$19000<\operatorname{Re}<80000$

Incidence of An angle of $45^{\circ}$

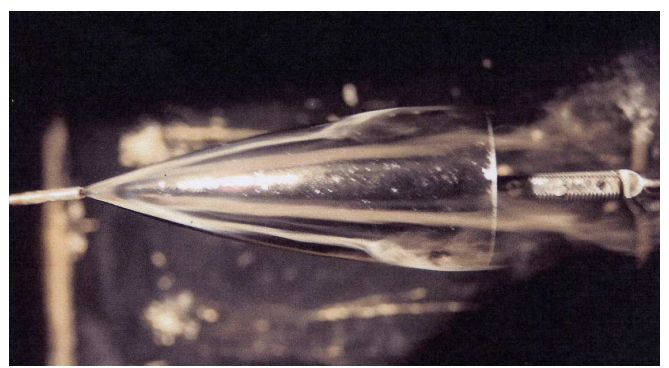

View $n^{\circ}$ 3. At $45^{\circ}$ incidence, I see the phenomenon of pulse bursts outside vortex that rises to the apex and the angle between 'le outer vortices and $\omega 2$ 26, 6 and the angle between the main vortices is $\omega$ 12.9.

$$
\begin{aligned}
& \beta=52^{\circ} \quad \mathrm{i}=45^{\circ} \quad \omega 1=20,7^{\circ} \quad \omega 2=30^{\circ} \\
& 19000<\operatorname{Re}<80000
\end{aligned}
$$

Incidence of An angle of $50^{\circ}$

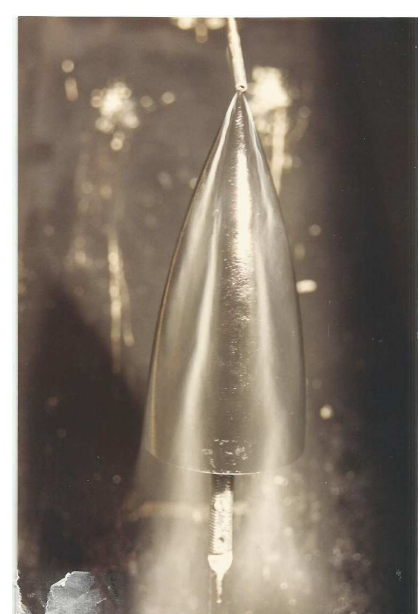

View $n^{\circ}$ 4. The breakdown phenomenon of the secondary vortices first appears as from an angle of incidence of $40^{\circ}$.

$\beta=52^{\circ} \quad \mathrm{i}=50^{\circ} \quad \omega 1=24,1^{\circ} \quad \omega 2=35.3^{\circ}$

$19000<\operatorname{Re}<80000$ 
Incidence of An angle of $58^{\circ}$

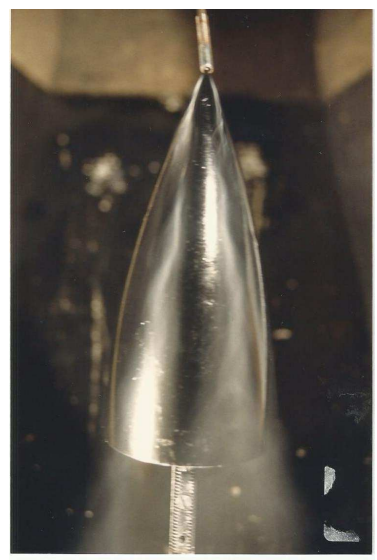

View $\boldsymbol{n}^{\circ} 5$. The formation of two vortex torques is detected, separated by an air corridor (a non-vortex passage) while the breakdown of the both main and secondary vortices begin. Angle of incidence of $55^{\circ}$.

$\beta=52^{\circ} \quad \mathrm{i}=58^{\circ} \quad \omega 1=28,2^{\circ} \quad \omega 2=40,1^{\circ}$

$19000<\operatorname{Re}<80000$

Incidence of An angle of $62^{\circ}$

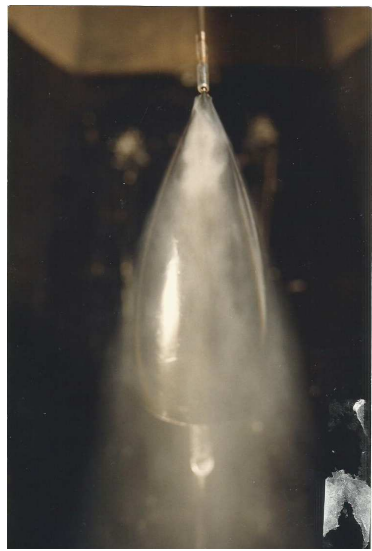

View $n^{\circ}$ 6. By increasing the incidence to $70^{\circ}$, the breakdown phenomenon of vortex structures becomes apparent, the flow of which, according to the incidence, swirl towards the apex of the give of revolution.

$\beta=52^{\circ} \quad \mathrm{i}=62^{\circ} \quad \omega 1=30^{\circ} \quad \omega 2=45^{\circ}$

$19000<\operatorname{Re}<80000$

The whole of these two air flows and of this passage is contained in a global angle of $45^{\circ}$ whereas the angle formed between the left- and right-hand edges of each of the two air flows is $30^{\circ}$. At higher incidences, the turbulence causes considerable diffusion of the smoke and therefore does not enable clear visualisations to be made of the vortex structures; the latter subsequently deteriorate by bursting into torch forms that are initially stationary and then are subjected to alternate movements before those movements become thereafter chaotic.

\section{Conclusion}

While, on a wide range of Reynolds, the preferential nature of the intervortex angles present on the upper surface of delta and gothic wings and of ogives of revolution would seem to be fully catalogued, the very existence of the law of filiation relative to such slender bodies expresses a certain universality of behaviour and reveals the fundamental feature of our study.

At the present time, however, no complete theoretical approach would seem to be capable of providing a straightforward explanation of the simplicity of these results. The progressive evolution from elementary vortices of the sheer flow before take-off towards a particularly stable vortex system, wherein spatial positioning reveals an original organisation, still remains today an enigma. It is, of course, difficult to prejudge the lines along which one or more future studies may follow, studies which could lead to a theoretical explanation. However, perhaps we may be permitted to note that the phenomena, in which the sine squared of an angle also plays a part, are created by the simple structures of stationary and unsteady fluid mechanics.

It is in this way that the flow - emitted by an ogive of revolution having a demi-span of $\theta$ at its summit on a tridimensional dipole with the same axis as that of the cone, or with its summit at the centre of a vortex ring equivalent to the dipole - is proportional to $\operatorname{Sin}^{2} \theta$. This is how energy emitted by an oscillating electromagnetic dipole (with properties analogous to those of the oscillating fluid dipole that plays a part in aerodynamics or in hydrodynamics) in a $\theta$ direction with regard to the axis of the dipole - is, energy too, proportional to $\operatorname{Sin}^{2} \theta$ or to $\cos ^{2} \theta=1-\sin ^{2} \theta$ in the case of the acoustic dipole. It is also a law in $\operatorname{Sin}^{2} \theta$ that gives the dependence, with regard to the angle of attenuation of the second sound thermal waves in liquid helium, by rectilinear vortices which form the $\theta$ angle with the direction of the propagation of this wave.

It is, moreover, by coupling this law with the concept of that preferential angle, formed by helicoidally vortices with their axes, that the authors of the papers referred to in [1] and [2] interpreted the discontinuous angular behaviour of these vortex systems in liquid helium [1, 2 and 19].

Finally, and this ultimate remark is probably not the least important one, the suction force, to which a profile - an infinitely thin and localised plane, let us remember - is subjected in the immediate vicinity of its leading edge, is, that force, too, proportional to the sine squared of an angle, in this case the angle of incidence.

As concerns the possible links, of the phenomena we have described, with the properties of an emission or of an absorption of a flow or of a wave - whose source may be dipolar or multipolar - it is perhaps interesting to note that the range of speeds of a tridimensional dipole \{characterised by the angle between the radius vector of a point of the fluid and the speed of this fluid $\}$ is linked to the angular positioning of this point, with regard to the dipole \{characterised by the polar angle between the axis of the dipole and the radius vector\}, by a series of striking correspondences between the most simple preferential angles. Moreover, if we now consider the force of interaction between two dipoles of relatively simple orientation - the most simple is one with two parallel dipoles, but numerous other layouts give equally curious results - the range 
of interaction forces \{characterised by the angle between the radius vector joining the two dipoles with this interaction force\}, possesses, in its turn, together with the two other ranges of relative positioning and of speeds \{characterised as described above\}, two new entireties of quite striking correspondences E. TRUCKENBRODT [24].

Where the notable orientations of interaction forces between two parallel dipoles are concerned, and with regard to the common direction of the axes of these dipoles, we have extracted a few particular cases from the general calculations made by W. KÖNIG [25] and from his final result given in J.W-C. RAYLEIGH's very famous book on acoustics [26].

These references contain expressions of : the components of the force exerted by one sphere on another in the presence of a uniform wind pattern to infinity; where the fluid flow is perfect; the line joining the centres of spheres forming the $\theta$ angle with the direction of the wind to infinity - this force is the same as that exerted by one sphere on another when those spheres are moving parallel to each other and at the same speed in an immobile fluid to infinity - but it is known that each of these spheres is equivalent to a tridimensional dipole.

The sole particular cases commented on by W. KÖNIG [25] and J.W-C. RAYLEIGH [26] are those where the centres of the spheres are aligned, \{i.e. in the direction of the wind\}, and where these spheres therefore exert on each other a repulsion force $\{$ i.e. perpendicularly to the wind $\}$ with, in this case, a gravitational interaction force which explains the formation of very fine powder ridges, perpendicular to the axis of a sound tube, within its antinodes (ventral segments) of vibration.

But a whole series of other consequences from the general formulae found in references [25] and [26] seem, they too, to be very significant. One of the most important of these particular cases seems to us to be that where the interaction force between two parallel dipoles is itself parallel to them. Formula $n^{\circ} 4$ on page 47 of reference [26] immediately shows that this case corresponds to the $\theta$ angle, cancelling the Legendre polynomial $1-5 \cos ^{2} \theta$, i.e. at

$$
\cos \theta=\frac{1}{\sqrt{5}}=\frac{2}{\sqrt{4(4+1)}}=\cos \theta_{42}
$$

according to the defining formula of preferential angles given at the beginning of this paper.

This angle $\theta_{42}=63.4^{\circ}$ is, moreover, the angle between the diagonals of the famous "Golden Rectangle" discovered by architects and employed by them from time immemorial [21].

In this same train of thought, it is striking to note, in references [27 to 29] the role played systematically by the angle $\theta_{32}=54.7^{\circ}$ (cancelling the Legendre polynomial 1$3 \cos ^{2} \theta$ ) in the sound emission of an axisymetric jet and of two interaction forcing vortex rings or of one forcing vortex ring in the presence of a sphere.

In short, many other well-known hydrodynamic and aerodynamic phenomena are rich in preferential angles, the theory of which has at some or other been fully elaborated. This is the case found in the very subtle and elegant theory described in particular in the works of H. LAMB [30] and of
J. LIGHTHILL [31]. In the wake, the crests of waves, in a curvilinear triangle form, will in fact each disappear at two counter flow points, the alignment of which, along two righthand sides, determines a total span of the wake at twice $19.4^{\circ}$ here and there of the axis of this wake, axis with which the counterblow tangents, associated with the crests, form an angle of $54.7^{\circ}$ while also forming with each corresponding edge of the wake an angle of $35.3^{\circ}$ \{i.e. $\left.54.7^{\circ}-19.4^{\circ}\right\}$.

It is there where the following relation is to be found, never interpreted before now, in terms of preferential angles :

$$
\begin{gathered}
\theta_{32}=\theta_{22}+\theta_{88} \\
54,7^{\circ}=35,3^{\circ}+19,4^{\circ}
\end{gathered}
$$

The link between the wake of a ship, being the result of the combination of bidimensional surface waves shed in various directions, and the phenomena described above may appear at first sight to be very mysterious. We may, however, be permitted to reason that the paper by E. LEVI [32] under the title "An oscillating approach to turbulence", so suggestively illustrated by figure $\mathrm{n}^{\circ} 1$ on page 352 of his study an illustration which represents the frontier of a wake or of a maximum layer as a swell induced by the emission of vortices $\}$ perhaps provides the starting point of a profitable line of further research which could lead to a better understanding of the omnipresence of preferential angles and of their filiations in tridimensional flows, and in particular in those developed around slender bodies.

The essential question to be pursued, and one which remains as yet to be entirely addressed, seems to us primarily to lie with structures and wave propagation. What is required is the explanation of the link between those preferential angles, which appear in structures exterior to the borderline layer, and structures, which would also probably need to be termed preferential angles, to be found in the forms and modes of wave propagation. The latter have recently been the subject in a close study of "the coherent structures of turbulence", structures that are, in particular, present in laminar-turbulent transition zones or in zones of anisotropic turbulence, especially where they relate to layers.

\section{Notations}

$\theta$

$\theta_{\ell \mathrm{m}} \quad$ prefere

$\ell, \mathrm{m} \quad$ : whole numbers such as $\ell \geq \mathrm{m}$

$\beta \quad$ : apex (included) angle

$\mathrm{h} \quad$ : height of the ogive of revolution

$\mathrm{R}$ : radius of the base of the ogive of revolution

I : incidence

$\mathrm{V}_{\mathrm{o}} \quad$ : speed of the flow to infinity upstream

Re : Reynolds' number

$\omega_{1} \quad$ : the main or interior intervortex angle

$\omega_{2}$ : the secondary or exterior intervortex angle

$\alpha \quad$ : the main intervortex angle present on the upper

$\alpha \quad$ surface of delta or gothic wings 


\section{References}

[1] M. LERAY and M. FRANCOIS Stability of a vortex lattice in the presence of a superflow. Physics letters 34A 14 April 1971, pp 431-432.

[2] J.P. DEROYON, M.J. DEROYON and M. LERAY. Experimental evidence of macroscopic spatial quantification of angular momentum in rotating. Hélium. Phvsics letters, A45, September 1973, pp 237-238.

[3] H. WERLE Structure des décollements sur les ailes cylindriques . La recherche aérospatiale, $n^{\circ} 3$, Mai 1986, pp 13-19.

[4] H. WERLE Tourbillons d'ailes minces très élancées. $L a$ recherche aérospatiale, $n^{\circ}$ 109, Novembre-Décembre 1965, pp 3-12.

[5] H. WERLE Interaction tourbillonnaire sur voilures en delta fixées ou oscillantes (visualisation hydrodynamique ). La recherche aérospatiale, $n^{\circ}$ 2, Mars-Avril 1980, pp 43-68.

[6] H. WERLE et M. GALLON Etude par visualisation hydrodynamique de divers procédés de contrôle d'écoulements décollés . La recherche aérospatiale, $n^{\circ} 2$, Mars-Avril 1976, pp 75-94.

[7] H. WERLE Le décollement sur le corps de révolution à basse vitesse. La Recherche aéronautique $n^{\circ}$ 90, Septembre-Octobre 1962, pp l-14.

[8] H. WERLE Exploitation quantitative des visualisations d'écoulements obtenues dans les tunnels hydrodynamiques de l'ONERA. La recherche aérospatiale, $n^{\circ} 6$, Novembre-Décembre 1990, pp 49-72.

[9] H. WERLE Structure des décollements sur les ailes en flèche. La recherche aérospatiale, $n^{\circ}$ 2, Mars-Avril 1980, pp 85-108.

[10] J.L. SOLIGNAC, D. PAGAN et P. MOLTON Examen de certaines propriétés de l'écoulement à l'extrados d'une aile delta . Rapport technique 37/1147 AN, Septembre 1988.

[11] J.L. SOLIGNAC, D. PAGAN et P. MOLTON Etude expérimentale de l'écoulement à l'extrados d'une aile delta en régime incompressible. La recherche aérospatiale $n^{\circ} 6$, Novembre-Décembre 1989, pp 47-65.

[12] W. STAHL Experimental investigations of asymmetric vortex flow behind elliptic cones at incidences. AIAA Journal Vol 3, $n^{\circ}$ 5.1993, pp 966-968.

[13] W. STAHL, A. ASGHAR Suppression of vortex asymmetry behind circular cones. AIAA Journal, Vol 28, $n^{\circ} 6,1990, p p$ 1138-1140.

[14] W. STAHL, M. MAHMOOD and A. ASGHAR Experimental investigations of the vortex flow on delta wings at high incidence. AIAA Journal, Vo1 .30, n 4, 1992, pp 1027-1032.

[15] A. AYOUB, STANFORD UNIVI SITY, C.A. and B.G Mc LAGHLAM, NASA, Research Center, Mofliet Field CA. Slender delta wing at high angle of attack, flow visualisation study . AIAA Journal, June 8-10, 1987, Honolulu, Hawaï.

[16] O.K. REDINIOTIS, H. STAPOUNTZIS and D.P. TELIONIS Periodic Vortex Shedding over Delta Wings. AIAA Journal, Vol 31, $n^{\circ}$ 9, September 1993, pp 1555-1562.

[17] M. ROY Caractère de l'écoulement autour d'une aile en flèche accentuée. C.R.Acad. Sci. Paris, t. 234, 1952, pp 2501-2503.

[18] R. LEGENDRE Ecoulement au voisinage de la pointe avant d'une aile à forte flèche aux: moyennes incidences. $L a$ recherche aéronautique $n^{\circ} 30,1952$ et $n^{\circ} 31,1953$.

[19] M. LERAY, J. P. DEROYON, M.J. DEROYON et C. MINAIR Critères angulaires de stabilité d'un tourbillon hélicoïdal ou d'un couple de tourbillons rectilignes, rôle des angles privilégiés dans l'optimisation des ailes, voiles, coques des avions et des navires. Communication à l'association technique maritime et aéronautique (ATMA). Publication dans le bulletin de l'ATMA, Session 85, Paris 1985, pp 511-529.

[20] C. MINAIR Les angles privilégiés, grands invariants et universaux : une approche par la dynamique des fluides, l'esthétique et physio-biologie. Thèse de doctorat d'état, Université de Valenciennes, Octobre 1987.

[21] M. LERAY Dialogue du physicien et de l'esthète : les Angles Privilégiés Communication et langage, $n^{\circ} 45,1980$, pp 49-69.

[22] A. ABENE Etude systématique des positions et de la stabilité des structures tourbillonnaires au dessus d'ailes ogives et de cônes. Thèse de doctorat. Université de Valenciennes, Juillet 1990.

[23] M. BENKIR Persistance et destruction des structures tourbillonnaires concentrées ou partielles au dessus des ailes delta. Thèse de doctorat. Université de Valenciennes, Avril 1990.

[24] E. TRUCKENBRODT Fluidmechanik band Elementaire strömungsvorgänge dichteversanderlicher fluide sowie potential und gnenzschichtströmungen. Springer Verlag, Berlin, 1980, § 5.3,2.6 d Räumliche Dipole Strömung, pp 167-168.

[25] W. KÖNIG Wied Ann, Tome XLII 1891, pp 353-549.

[26] J .W-Ç. RAYLEIGH Theory of sound. Volume II, second edition, $\S 253$ b. Striafion in Kundt's tubes 1896, Dover Publications. New York, 1945, pp 45-47.

[27] W. MÖHRING Modelling low Mach number noise in mechanics of sound generation in flows. IUTAM/ICA/ALAA Symposium, Göttingen, Germany, August 28-31 1979, Edited by E.A. Müller, Springer Verlag, Berlin. 1980, pp 85-96.

[28] C.D. MÙLLER, F. OBERMEIER Vortex sound, in vortex motion. Edited by H. Hasimoto and T. Kambe, North Holland, Amsterdam, 1988, pp 43-51.

[29] T. MINOTA, T. KAMBE and T. MUKARAMI Acoustic emission from interaction of a vortex ring with a sphere, in vortex motion. Edited by H. Hasimoto and T. Kambe, North Holland, Amsterdam, 1988, pp 357-362.

[30] H. LAMB Hydrodynamics. Sixth Edition 1932, reprinted by Dover Publications, New York 1945, § 256, Ship Waves, pp 433-440.

[31] J. LIGHTHILL Waves in fluids. Cambridge University Press, UK, 1978, § 3.10, Ship Waves, pp 269-279.

[32] E. LEVI An oscillating approach to turbulence in unsteady turbulent shear flows. IUTAM Symposium, Toulouse, France, May 5-8 1981, Edited by R.Michel, J. Cousteix and R. Houdeville, Springer Verlag, 1981, pp 348-358. 
[33] A. ABENE La détermination des positions relatives des structures tourbillonnaires au-dessus des ailes ogives et des cônes. Habilitation à diriger des recherches, 9 Octobre 2002.

[34] V. DUBOIS Etude détaillée des structures tourbillonnaires à l'extrados de corps élancés simples, complexes et de révolutions. Thèse de doctorat le 16 Décembre 2005.

[35] A. ABENE and V. DUBOIS Fundamental aspects of the vortex flow on cones. Angular characterisation of hyperlifting vortex torques; the law of filiation Canadian Journal of Physics, $n^{\circ}$ 86, Aôut 2008 .

[36] A. ABENE, V. DUBOIS et M. SI YOUCEF Etude expérimentale sur des capteurs solaires à air : application pour le séchage de la prune. Revue internationale d'héliotechnique, $n^{\circ} 33$, pp 2-18, Printemps 2006.

[37] A. ABENE and V. DUBOIS, « A experimental study of air heating plane solar panels as used in drying mangoes ", International Journal of Energy Research, ref ER-09-1016, Juin 2009.

[38] A. ABENE "Visualisation of Vortex Structures Developed on the Upper Surface of Double-Delta Wings", J Aeronaut Aerospace Eng 2:118, doi:10.4172/2168-9792.1000118. Septembre 2013 